\title{
NÚMERO DE CASOS DE HEPATITES ADQUIRIDAS EM ACIDENTES DE TRABALHO NO BRASIL ENTRE 2009 E 2018
}

\section{ARTIGO ORIGINAL}

ALMEIDA, Naara Perdigão Cota de ${ }^{1}$

LIMA JÚNIOR, Idelbrando Araújo ${ }^{2}$

AZEVEDO, Lucas do Rêgo Góes ${ }^{3}$

MARTINS, Romulo Maia ${ }^{4}$

MAGALHÃES, Gustavo Aurélio Linhares ${ }^{5}$

DIAS, Claudio Alberto Gellis de Mattos ${ }^{6}$

ARAÚJJO, Maria Helena Mendonça de ${ }^{7}$

OLIVEIRA, Euzébio de ${ }^{8}$

${ }^{1}$ Acadêmico do curso de Medicina da Universidade Federal do Patrá (UNIFAP).

${ }^{2}$ Acadêmico do curso de Medicina da Universidade Federal do Patrá (UNIFAP).

${ }^{3}$ Acadêmico do curso de Medicina da Universidade Federal do Patrá (UNIFAP).

${ }^{4}$ Acadêmico do curso de Medicina da Universidade Federal do Patrá (UNIFAP).

${ }^{5}$ Acadêmico do curso de Medicina da Universidade Federal do Patrá (UNIFAP).

${ }^{6}$ Doutor em Teoria e Pesquisa do Comportamento (UFPA). Professor e Pesquisador no Instituto Federal do Amapá (IFAP), campus Macapá, AP. Professor e Pesquisador no Programa de Pós-Graduação em Educação Profissional e Tecnológica (ProfEPT), IFAP, campus Santana.

${ }^{7}$ Mestra em Ensino e ciências da Saúde. Professora e pesquisadora na Universidade Federal do Amapá (UNIFAP), campus Macapá, AP.

${ }^{8}$ Doutor em Doenças Tropicais (UFPA). Professor e Pesquisador na v Universidade Federal do Pará (UFPA), Campus Castanhal, PA. 
DENDASCK, Carla Viana ${ }^{9}$

FECURY, Amanda Alves ${ }^{10}$

ALMEIDA, Naara Perdigão Cota de. Et al. Número de casos de hepatites adquiridas em acidentes de trabalho no Brasil entre 2009 e 2018. Revista Científica Multidisciplinar Núcleo do Conhecimento. Ano 05, Ed. 12, Vol. 10, pp. 28-37. Dezembro de 2020. ISSN: 2448-0959, Link de acesso: https://www.nucleodoconhecimento.com.br/saude/casos-de-hepatites

\section{RESUMO}

As hepatites virais são um grave problema de saúde pública no mundo e no Brasil. São doenças de notificação compulsória instituída pelo Ministério da Saúde do Brasil (MS). Os registros das pessoas acometidas devem ser feitos no Sistema de Informação de Agravos de Notificação (SINAN), que deverá notificar todos os prováveis casos, os confirmados e os surtos. O objetivo deste trabalho é quantificar o número de casos de hepatites adquiridas em acidentes de trabalho no Brasil entre 2009 e 2018. É um estudo é uma análise quantitativa observacional retrospectiva acerca dos dados epidemiológicos investigados. Nesse sentido, foram realizadas pesquisas nas bases de dados do portal nacional DATASUS (https://datasus.saude.gov.br/). Existe contribuição efetiva dos acidentes de trabalho para os atuais índices de incidência de hepatites virais em território brasileiro, bem como para a diminuição da qualidade de vida dos trabalhadores - especialmente os da saúde. Incoerências entre dados epidemiológicos registrados no SINAM e estudos

9 Doutora em Psicanálise (SEMINÁRIO INTERNACIONAL DE TEOLOGIA). Pesquisadora do Centro de Pesquisas e Estudos Avançados (CEPA). Doutoranda em Comunicação e Semiótica (PUC SP).

${ }^{10}$ Doutora em Doenças Tropicais (UFPA). Professora e pesquisadora na Universidade Federal do Amapá (UNIFAP), campus Macapá. Professora e pesquisadora no Programa de Pós- Graduação em Ciências da Saúde (UFPA). Pró-Reitora de Pesquisa e Pós-Graduação na Universidade Federal do Amapá (UNIFAP). 
da literatura podem demonstrar a presença de subnotificação. Devido à relativa escassez e contradição de estudos, não há um perfil bem estabelecido para a contaminação nos serviços da saúde, havendo necessidade de mais estudos acerca da temática.

Palavras-chave: Epidemiologia, hepatite, acidente de trabalho.

\section{INTRODUÇÃO}

As hepatites virais são um grave problema de saúde pública no mundo e no Brasil. Estimativas sugerem que bilhões de pessoas já tiveram contato com algum tipo de vírus da hepatite e milhões destes são pacientes crônicos (BRASIL, 2005). As hepatites são doenças provocadas por diferentes agentes etiológicos. Possuem em comum o hepatotropismo, apresentando características clínicas e laboratoriais semelhantes, porém com importantes particularidades na epidemiologia dos casos (BRASIL, 2016). Apesar de ter uma distribuição universal é possível notar diferença de magnitude dos diferentes agentes etiológicos entre países e até mesmo em diferentes regiões de um mesmo país, como o Brasil. Certas condições podem predispor o aumento de tais doenças, como higiene de má qualidade e a falta de saneamento básico. A melhoria desses fatores, aliada às novas técnicas de diagnóstico das hepatites $\mathrm{C}$ e a ampliação dos programas de vacinação da Hepatite B, são avanços importantes para reduzir os índices de pacientes acometidos (BRASIL, 2016; NUNES et al., 2020).

As hepatites virais são doenças de notificação compulsória instituída pelo Ministério da Saúde do Brasil (MS). Os registros das pessoas acometidas devem ser feitos no Sistema de Informação de Agravos de Notificação (SINAN), que deverá notificar todos os prováveis casos, os confirmados e os surtos (BRASIL PORTARIA 2014, 2016).

Os acidentes de trabalho representam um relevante evento adverso e agravante ocorrido em atividades laborais, destacando-se como mecanismo de contágio de doenças infecciosas, tais como as hepatites virais, com grande importância para a saúde pública (GARCELL, 2016). Tais acidentes além de representar importância na 
saúde pública tem impactos na vida dos acidentados, estes podendo afetar sua qualidade de vida e saúde (BULHÕES, 1998).

Nesta perspectiva, os trabalhadores têm em comum os perfis de adoecimento e morte da população de forma geral, em função de sua idade, gênero, grupo social ou inserção em um grupo específico de risco. Somando-se a isso, os trabalhadores podem, ainda, adoecer ou morrer por causas relacionadas ao trabalho, em consequência da profissão que exercem ou exerceram, ou pelas condições adversas em que seu trabalho é, ou foi, realizado (BRASIL, 2001).

A vigilância epidemiológica, neste contexto, torna-se uma estratégia eficiente na prevenção e controle das doenças, que pode reforçar a ideia de autocuidado e compromisso dos profissionais de saúde do Brasil (Cordeiro et al., 2018). Com o intuito de reforçar o programa de controle epidemiológico das hepatites no Brasil o MS instituiu prioridade no DCCI/ SVS/MS para o biênio 2019-2020 das ações na prevenção e combate às hepatites virais (MS, 2020).

\section{OBJETIVO}

Quantificar o número de casos de hepatites adquiridas em acidentes de trabalho no Brasil entre 2009 e 2018.

\section{METODOLOGIA}

O presente estudo é uma análise quantitativa observacional retrospectiva acerca dos dados epidemiológicos investigados. Nesse sentido, foram realizadas pesquisas nas bases de dados do portal nacional DATASUS (https://datasus.saude.gov.br/), referente às notificações de contaminação de hepatites virais em acidentes de trabalho entre 2009 e 2018.

Para tanto, os parâmetros de análise incluídos foram os números de casos separados por ano, a quantificação de ocorrências em cada região do país, a separação do contágio ocorrido entre homens e mulheres, bem como a distribuição da faixa etária 
acometida e o número de notificações segundo o tipo de vírus da hepatite contaminante.

A obtenção de dados ocorreu no mês de junho de 2020. Em seguida, os dados colhidos foram compilados, em seguida tabulados no programa Excel, componente do pacote Office da Microsoft Corporation e, por fim, analisados em conjunto com a pesquisa literária levantada.

\section{RESULTADOS}

De acordo com os dados especificados na figura 1, dentre os anos investigados, 2009 foi o que obteve maior número de casos de hepatites virais adquiridas em acidentes de trabalho no Brasil, registrando 147 ocorrências. Já 2018 foi o ano em que o número de casos foi menor, 80. Ou seja, em 10 anos, houve um decréscimo de $45,5 \%$ no número de notificações.

Figura1 Mostra o número de casos de hepatites virais adquiridas em acidentes de trabalho no Brasil, entre 2009 e 2018.

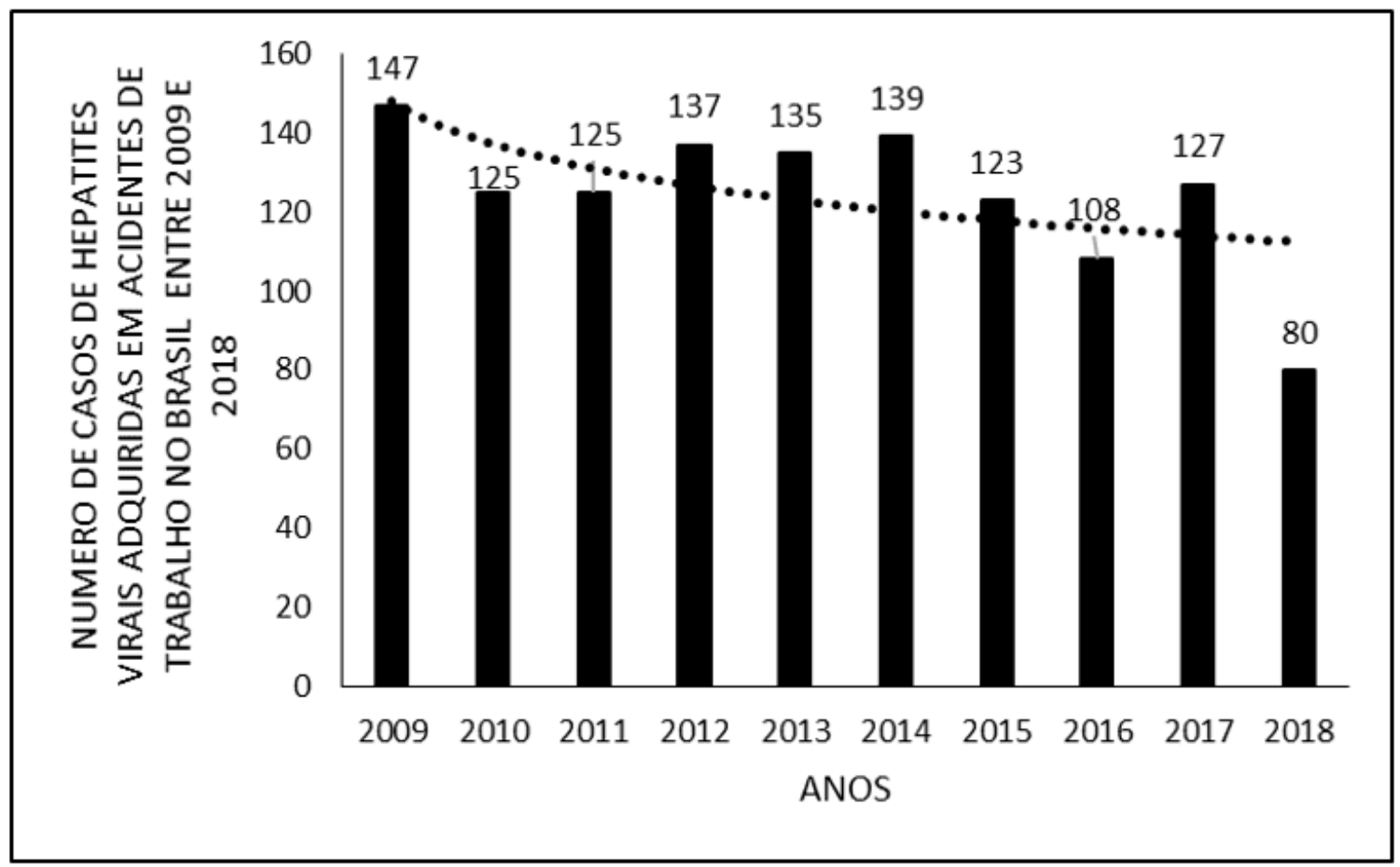


O número de casos de hepatites virais adquiridas em acidentes de trabalho registrados variou conforme as regiões brasileiras analisadas (figura 2). O Sul correspondeu ao maior número de contaminações, 540. Já o Norte ao menor, com 92 casos notificados.

Figura 2 Mostra o número de casos de hepatites virais adquiridas em acidentes de trabalho, por regiões do Brasil, entre 2009 e 2018.

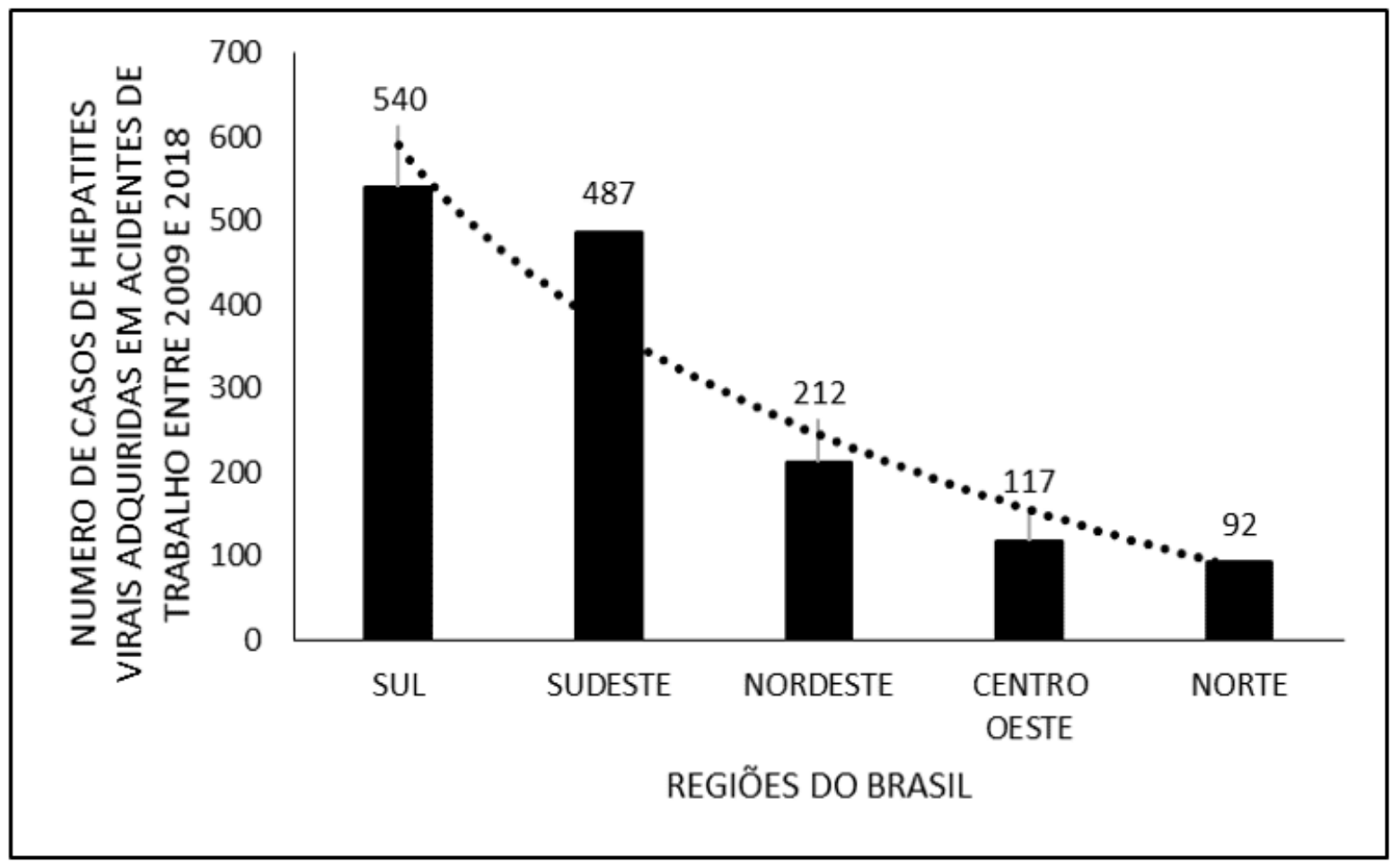

No que tange às informações contidas na Tabela 1, separando-se os casos de hepatites virais adquiridas em acidentes de trabalho entre 2009 e 2018 por sexo biológico, mais de $60 \%$ das contaminações correspondem às mulheres, isto é, 909 casos, enquanto que 539 dos casos correspondem aos homens. 
Tabela 1 Mostra o número de casos de hepatites virais adquiridas em acidentes de trabalho, por sexo biológico, entre 2009 e 2018.

\section{Sexo \\ Biológico \\ Número de casos \\ Feminino \\ 909 \\ Masculino \\ 539}

Com relação à distribuição dos casos por faixa etária, entre 2009 e 2018 (figura 3), correspondente às contaminações adquiridas em acidentes de trabalho, vinte e um (21) deles foram adquiridos abaixo dos 19 anos. Mil duzentos e quarenta e seis (1246) entre 20 e 59 anos, representando a faixa com maior contaminação, tendo em vista esta ser a faixa que comporta o maior número de trabalhadores do país, e cento e oitenta e uma (181) contaminações a partir dos 60 anos de idade.

Figura 3 Mostra o número de casos de hepatites virais adquiridas em acidentes de trabalho, por faixa etária (anos), entre 2009 e 2018.

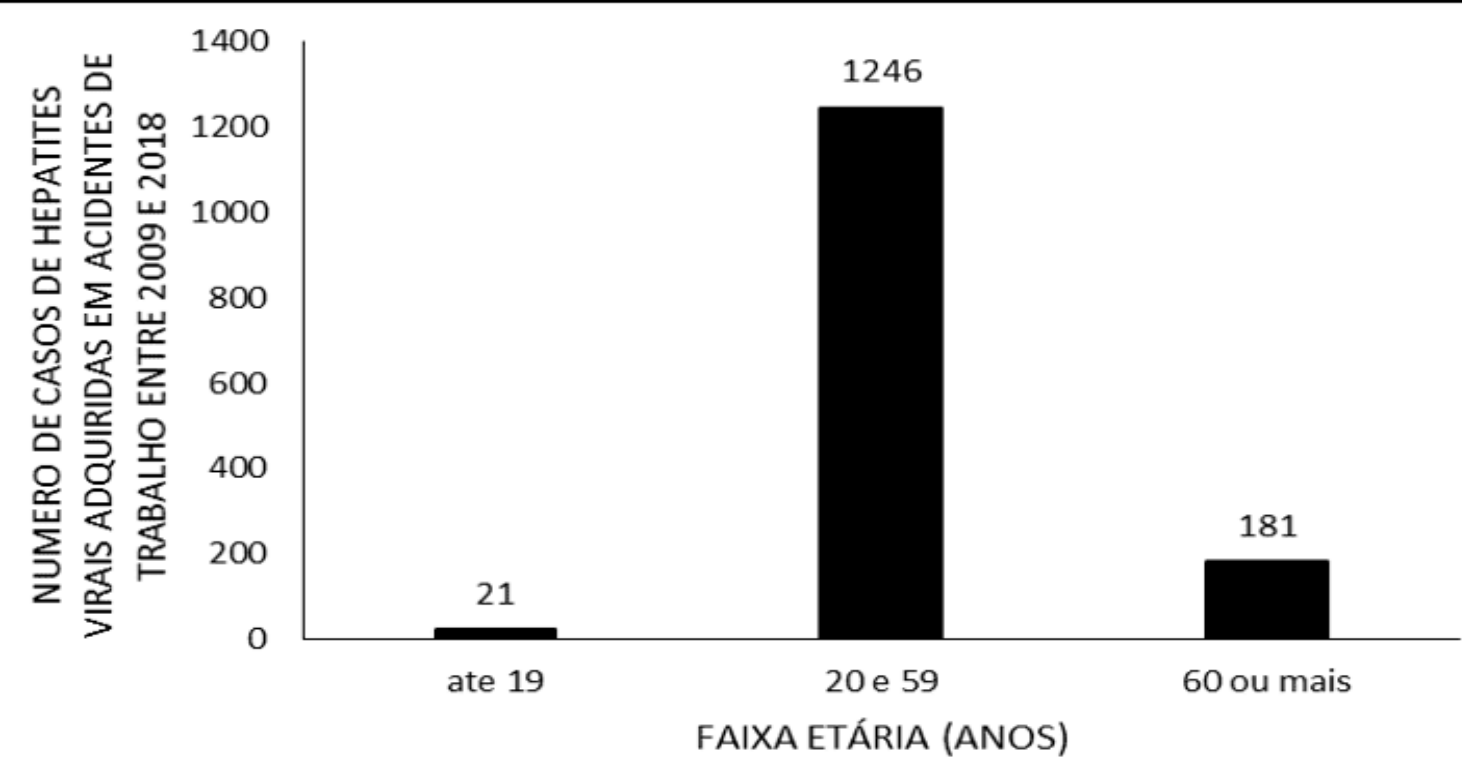


A contaminação por hepatite adquirida em acidentes de trabalho entre 2009 e 2018 variou conforme seus tipos (classificação etológica) (figura 4). Dentre as notificações realizadas, os tipos com maior incidência foram o $C$, com 869 casos e $B$, com 482 . Os de menor incidência foram o tipo B+D e $E$, ambos com 1 caso.

Figura 4 Mostra o número de casos de hepatites virais adquiridas em acidentes de trabalho, por classificação etiológica (tipos) entre 2009 e 2018.

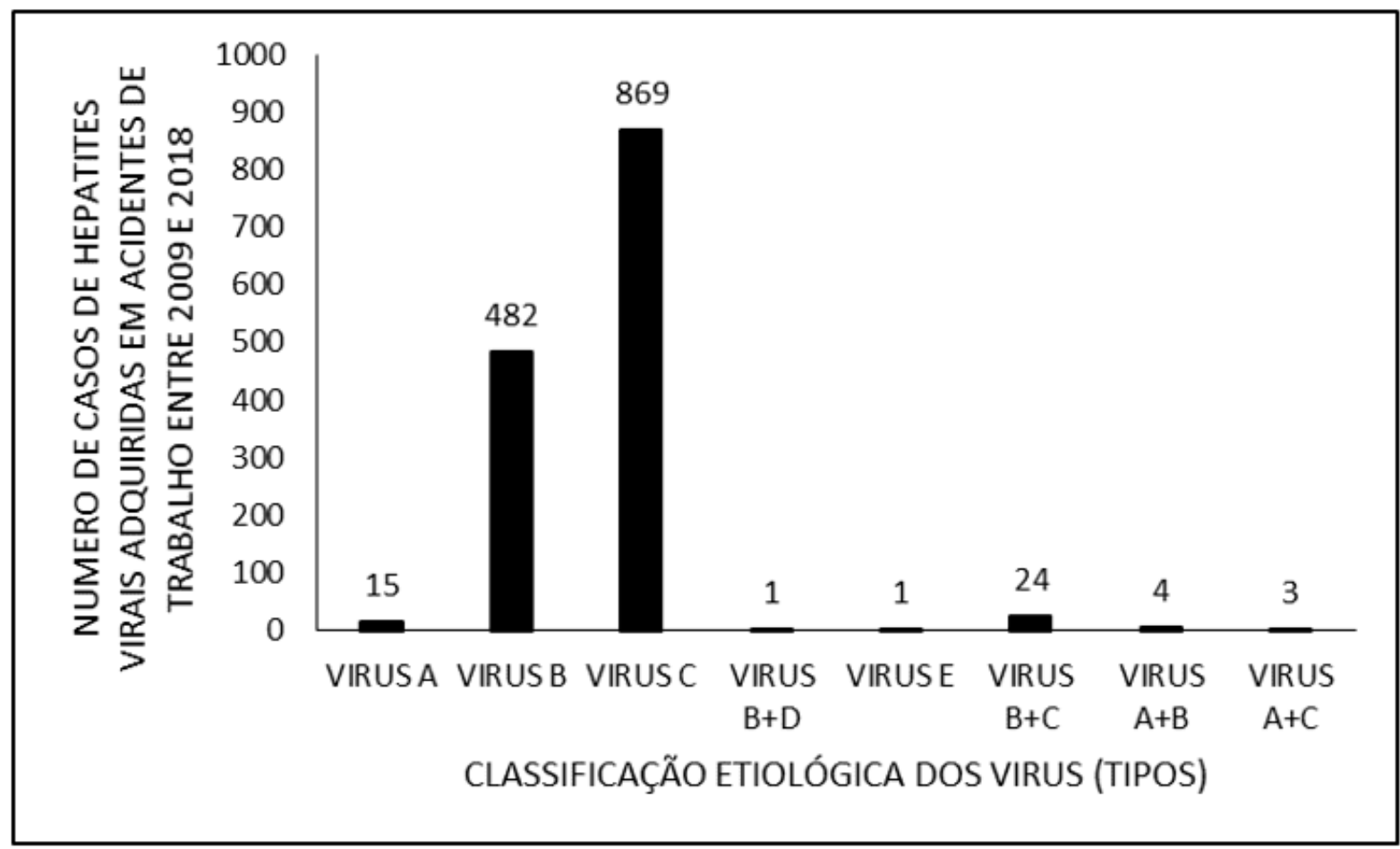

\section{DISCUSSÃO}

As hepatites virais estão entre as doenças infecciosas ainda muito prevalentes no Brasil e, segundo dados advindos do Ministério da Saúde, houveram 718.837 pessoas notificadas de 1997 a 2018 (BRASIL, 2018). Através da análise quantitativa destes dados, é possível observar que dentre os trabalhadores regularizados, os profissionais de saúde são uma das classes mais expostas à contaminação por esses vírus através de acidentes em seu ambiente laboral, e que suas causas são potencialmente evitáveis segundo o trabalho de Vieira et al (2011). 
Os dados referentes a incidência dos casos envolvendo hepatites virais decorrentes de acidentes de trabalho estão em consonância com outras análises similares presentes no trabalho de Spagnuolo et al (2008). A grande parte dos casos por número de habitantes encontram-se na região sudeste e sul do país com cerca de 540 e 487 casos notificados respectivamente, o que pode ser explicado tanto pela concentração populacional e profissional, quanto pelo grande número de serviços de saúde concentrados nesse espaço (CORDEIRO, 2018).

Em relação ao sexo, o mais acometido é o sexo feminino, uma vez que os acidentes estão relacionados majoritariamente às equipes de enfermagem, o que é confirmado no trabalho de Santos et al (2013). A Fundação Oswaldo Cruz realizou uma pesquisa em 2015, traçando o perfil da equipe de enfermagem no Brasil, o que mostrou um resultado de $85,1 \%$ de pessoas do sexo feminino realizando essas atividades, com isso, têm-se uma relação clara com a incidência elevada no sexo feminino $(62,7 \%)$ encontrada neste estudo (FIOCRUZ, 2013).

A faixa etária em que houve mais casos foi a de 40 a 59 anos, o que diverge de alguns estudos realizados em hospitais no Brasil, em que o grupo etário mais acometido era mais jovem, abaixo dos 40 anos (SANTOS, 2013; VIEIRA, 2011). A informação obtida no DATASUS pode relacionar-se com a impressão de que os profissionais mais experientes têm a tendência de darem mais margem ao erro ao realizarem seus procedimentos devido ao excesso de confiança, por consequência, deixam de atentarse à detalhes fundamentais de segurança individual (RODRIGUES, 2017).

O tipo de mais notificado foi o da hepatite $C$, segundo os dados pesquisados pelo DATASUS de 2009 a 2018, dado que confirma com alguns trabalhos da literatura, mas que também diverge de outros que indicam que a forma mais incidente de contaminação foi o da hepatite B. Até o presente momento ainda não é bem estabelecido qual é o perfil de contaminação mais incidente nos serviços de saúde no território brasileiro (VIEIRA, 2011).

A forma de acidente mais comum relatada em artigos científicos é através da manipulação de insumos perfurocortantes causando lesões cutâneas, principalmente 
relacionados à acidentes com agulhas e descarte dos materiais em locais inadequados, o não uso de equipamentos de proteção individual (SPAGNUOLO, 2011; CORDEIRO, 2019). Os principais motivos relacionados com a alta incidência destes tipos de acidentes é a alta jornada de trabalho, condições insalubres, estresse excessivo em plantões e ambiente de trabalho além de baixa educação continuada e atualização na formação desses profissionais (BARBOSA, 2017).

As medidas que devem ser reforçadas são: capacitação e treinamento das equipes multiprofissionais, revisão das técnicas de aplicação de injetáveis, adoção de protocolos de segurança, aquisição de dispositivos especializados e promoção de ambientes mais seguros. As exposições percutâneas foi a maioria, principalmente em membros superiores, sendo as mãos o local mais atingido devido ao manuseio de insumos hospitalares e à realização de procedimentos. A alta incidência desse tipo de exposição ocupacional reforça a necessidade de vigilância e capacitações contínuas sobre o manejo de objetos perfurocortantes (MARZIALE, 2014).

Além disso, a profilaxia pré e pós exposição destaca-se por ser uma alternativa largamente disponível, porém não tem a aderência desejada para uma classe de profissionais com risco rotineiro como os da saúde. Um trabalho realizado com 3084 trabalhadores na Bahia mostrou que apenas 2666 foram vacinados e destes, somente $59,7 \%$ completaram as 3 doses da vacina contra hepatite $B$, o que é preocupante já que a vacina é um dos principais modos de prevenção da doença (SOUZA, 2018).

Os acidentes de trabalho estão presentes no cotidiano dos profissionais de saúde e estão intimamente relacionados à diversos fatores modificáveis como uma capacitação inadequada, as condições de trabalho precárias, com falta de EPI's básicos para uma boa segurança e desconhecimento dos protocolos de profilaxia pré e pós exposição à contaminação, entre outros. Percebeu-se que no Brasil, ainda há uma quantidade considerável de subnotificação de casos, além de poucos estudos que elucidem a real situação quanto a esse tipo de acidente (SOUZA, 2018). 


\section{CONCLUSÃO}

Existe contribuição efetiva dos acidentes de trabalho para os atuais índices de incidência de hepatites virais em território brasileiro, bem como para a diminuição da qualidade de vida dos trabalhadores - especialmente os da saúde. Existe também importância dos acidentes de trabalho como causa para infecção por hepatites, e como mudanças de costumes aliadas a melhores condições de trabalho pode contornar a atual situação do Brasil.

Há correlação entre condições de saneamento e o risco de contaminação durante o acidente laboral, devendo, portanto, o empregador prover condições seguras de trabalho. Além disso, por se tratar de uma temática sempre presente e necessária, a prevenção de acidentes de trabalho e de contaminação deve ser sempre alvo de treinamentos e capacitações. Redução da exposição e condições de insalubridade e do estresse, e ambientes de trabalho mais seguros podem contribuir, também, para redução de acidentes entre trabalhadores da saúde.

Incoerências entre dados epidemiológicos registrados no SINAM e estudos da literatura podem demonstrar a presença de subnotificação. A partir do entendimento de que as notificações compulsórias servem de guia para implementação de políticas públicas, profissionais devem ser conscientizados acerca dessa necessidade. Nesse cenário - de uma possível redução na subnotificação - teremos números mais reais direcionando melhor a educação em saúde, voltada ao autocuidado e prevenção de acidentes em ambiente de trabalho, além da adoção de estratégias e protocolos que possam auxiliar no diagnóstico precoce e nas profilaxias pré e pós exposição. *Além disso, as inconsistências e incompletudes encontradas apontam para a necessidade de preenchimentos mais cuidadosos das fichas de notificação, a fim de que seja elevada a qualidade dos bancos de dados do SINAM.

Atenção especial deve ser dada às unidades de saúde e centros hospitalares das regiões sul e sudeste, decorrentes do elevado número absoluto e relativo ( $n^{\circ}$ de profissionais/habitantes) que elas possuem e que estão expostos a esse risco. 
Pelos acidentes de trabalho serem evitáveis, faz-se necessário medidas de profilaxia à infecção por hepatites virais, seja por formação continuada sobre técnicas corretas de manuseio e descarte de materiais contaminados ou por controle mais efetivo das jornadas de trabalho dos profissionais da saúde por parte dos gestores. Cuidado especial deve ser tomado para com aqueles profissionais com formação mais antiga e de idade mais avançada, que costumam ter muita confiança em suas habilidades, ao passo que possuem uma gradativa redução de reflexos e coordenação motora. Cursos de atualização e conscientização são imprescindíveis para grupo.

Por serem os perfurocortantes os instrumentos mais recorrentes nos acidentes laborais envolvendo infecção por doenças virais e por serem as mãos o local mais comum de contaminação em tais acidentes, há uma necessidade de devida cautela e do uso de EPIs por parte dos profissionais, além do emprego da técnica correta no seu manuseio e descarte em local adequado. Para isso, os gestores devem promover capacitações e conscientização, além de local e material adequado para descarte de perfurocortantes. Somado a isso, há necessidade de ações que aumentem a adesão dos profissionais às medidas de profilaxia pré e pós exposição, como a exigência de comprovação de esquemas de vacinação por parte das unidades de saúde.

Devido à relativa escassez e contradição de estudos, não há um perfil bem estabelecido para a contaminação nos serviços da saúde, havendo necessidade de mais estudos acerca da temática. Faz-se necessários mais estudos epidemiológicos, além do controle de qualidade destes e a redução de subnotificações com melhora na qualidade de preenchimento de fichas de notificação compulsória.

\section{REFERÊNCIAS}

BARBOSA, Adriana Sierra Assencio Almeida, DIOGO, Geandra do Amaral, SALLOTI, Selma Regina Axcar, SILVA, Sônia Maria Usó Ruiz. Subnotificação de acidente ocupacional com materiais biológicos entre profissionais de Enfermagem em um hospital público. Revista Brasileira de Medicina do Trabalho, 2017, 15(1), 12-17, 11 de maio de 2017. Disponível em: http://www.rbmt.org.br/details/209/pt- 
BR/subnotificacao-de-acidente-ocupacional-com-materiais-biologicos-entreprofissionais-de-enfermagem-em-um-hospital-publico. Acesso em 03/09/2020.

BRASIL. Ministério da Saúde. Secretaria de Vigilância em Saúde. Departamento de Vigilância Epidemiológica. Hepatites virais: o Brasil está atento, $2^{\underline{a}}$ edição. Brasília: Ministério da Saúde, 2005. 40 p.

BRASIL. Ministério da Saúde. Secretaria de Vigilância em Saúde. Departamento de Vigilância, Prevenção e Controle das Doenças Sexualmente Transmissíveis, Aids e Hepatites Virais. Manual Técnico para o Diagnóstico das Hepatites Virais, $2^{\underline{a}}$ edição. Brasília: Ministério da Saúde, 2016. 123 p.

BRASIL. Ministério da Saúde. Define a lista nacional de notificação compulsória de doenças, agravos e eventos de saúde pública nos serviços de saúde públicos e privados em todo território nacional, nos termos do anexo, e dá outras providências. Portaria no 204, de 17 de fevereiro de 2016. Brasília: Diário Oficial da União. 2016; Seção 1 (32): 23-4.

BRASIL. Ministério da Saúde. Secretaria de Vigilância em Saúde. Coordenação-Geral de Saúde do Trabalhador. Desigualdades no Mercado de Trabalho e Perfil de Adoecimento das Mulheres Trabalhadoras Brasileiras. Boletim Epidemiológico, Brasília, 2020, vol. 51, oㅡ 20, 28-38, maio de 2020.

BRASIL. Ministério da Saúde. Hepatite - Panorama atual. Portal da Saúde, 2018. Disponível em: <https://www.saude.gov.br/saude-de-a-z/hepatite-panorama-atual>. Acesso em: 03 de set. de 2020.

BULHÕES, Ivone. Riscos do trabalho de enfermagem. Revista Brasileira de Enfermagem, Brasília, vol. 47, ㄲo 1, p. 84, março de 1994. Disponível em: https://doi.org/10.1590/S0034-71671994000100017. Acesso em 03/09/2020

CORDEIRO, Técia Maria Santos Carneiro, D'OLIVEIRA JUNIOR, Argemiro. Qualidade dos dados das notificações de hepatites virais por acidentes de trabalho, Brasil. Revista Brasileira de Epidemiologia, São Paulo, vol. 21, e180006, 2018, 02 
de agosto de 2018. Disponível em: https://doi.org/10.1590/1980-549720180006. Acesso: 03/09/2020

GARCELL, Humberto Guanche, HERNANDEZ, Tania M. Fernandez, ABDO Elmusbasher Abu Baker, ARIAS, Ariadna Villanueva. Evaluation of the timeliness and completeness of communicable disease reporting: surveillance in the Cuban Hospital, Qatar. Qatar Medical Journal, Qatar, vol. 2014 (1), 50-56, 16 de junho de 2014. Disponível em: https://doi:10.5339/qmj.2014.9. Acesso em 03/09/2020.

NUNES, Filipe Sales. et al. Number of confirmed cases of viral hepatitis in Brazil between 2010 and 2015. Revista Científica Multidisciplinar Núcleo do Conhecimento. Year 05, Ed. 11, V ol . 25 , p p. 71 - 80 . N o v e m b e r 2020 . I

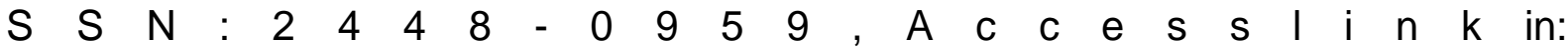
https://www.nucleodoconhecimento.com.br/health/viral-hepatitis,

DOI: 10.32749/nucleodoconhecimento.com.br/health/viral-hepatitis

SANTOS, Solange Sousa, DA COSTA, Nairicéia Alves, MASCARENHAS Márcio Dênis Medeiros. Caracterização das exposições ocupacionais a material biológico entre trabalhadores de hospitais no Município de Teresina, Estado do Piauí, Brasil, 2007 a 2011. Revista Epidemiologia e Serviços de Saúde, Brasília, 2013, vol. 22, no 1, 165-170, março de 2013. Disponível em: http://dx.doi.org/10.5123/S167949742013000100017. Acesso:03/09/2020.

SOUZA, Fernanda de Oliveira, DE ARAÚJO, Tânia Maria. Occupational exposure and hepatitis $B$ vaccination among health care workers. Revista Brasileira de Medicina do Trabalho, 2018, 16(1), 36-43, 11 de março de 2018. Disponível em: http://www.rbmt.org.br/details/291/en-US/exposicao-ocupacional-e-vacinacao-parahepatite-b-entre-trabalhadores-da-atencao-primaria-e-media-complexidade. Acesso: 03/09/2020

SPAGNUOLO, Regina Stella, BALDO, Renata Cristina Silva, GUERRINI, Ivan Amaral. Análise epidemiológica dos acidentes com material biológico registrados no Centro de Referência em Saúde do Trabalhador, Londrina, Paraná. Revista Brasileira de 
Epidemiologia, São Paulo, vol. 11, no 2, 315-323, junho de 2008. Disponível em: https://doi.org/10.1590/S1415-790X2008000200013. Acesso: 03/09/2020.

VIEIRA, Maria, PADILHA, Maria Itayra, PINHEIRO, Regina Dal Castel. Análise dos acidentes com material biológico em trabalhadores de saúde. Revista LatinoAmericano de Enfermagem, 2011, vol. 19, nº 2, 8 p, março de 2011. Disponível em: http:// www.scielo.br/pdf/rlae/v19n2/pt_15.pdf. Acesso: 03/09/2020.

Enviado: Dezembro, 2020.

Aprovado: Dezembro, 2020. 